Article

\title{
Bioglass-Incorporated Methacrylated Gelatin Cryogel for Regeneration of Bone Defects
}

\author{
Song Kwon ${ }^{1,+}$, Seunghun S. Lee ${ }^{2,+(\mathbb{D})}$, A. Sivashanmugam ${ }^{3}$, Janet Kwon ${ }^{2}{ }^{(0)}$, \\ Seung Hyun L. Kim ${ }^{2}$, Mi Yeon Noh ${ }^{2}$, Seong Keun Kwon ${ }^{2,4}$, R. Jayakumar ${ }^{3}$ (i) \\ and Nathaniel S. Hwang 1,2,5,* \\ 1 School of Chemical and Biological Engineering, the Institute of Chemical Processes, \\ Seoul National University, Seoul 08826, Korea; skwon2675@gmail.com \\ 2 Interdisciplinary Program in Bioengineering, Seoul National University, Seoul 08826, Korea; \\ lsean@snu.ac.kr (S.S.L.); jhkwon929@gmail.com (J.K.); lucykim619@gmail.com (S.H.L.K.); \\ mno9211@snu.ac.kr (M.Y.N.); otolarynx@snuh.org (S.K.K.) \\ 3 Center for Nanosciences and Molecular Medicine, Amrita Institute of Medical Sciences and Research Center, \\ Amrita Vishwa Vidyapeetham, Kochi 682041, India; sivasa19619@aims.amrita.edu (A.S.); \\ rjayakumar@aims.amrita.edu (R.J.) \\ 4 Department of Otorhinolaryngology-Head and Neck Surgery, Seoul National University Hospital, \\ Seoul 03080, Korea \\ 5 BioMAX/N-Bio Institute, Seoul National University, Seoul 08826, Korea \\ * Correspondence: nshwang@snu.ac.kr; Tel.: +82-2-880-1635 \\ $\dagger$ These authors contributed equally to this work.
}

Received: 12 July 2018; Accepted: 10 August 2018; Published: 14 August 2018

\begin{abstract}
Cryogels have recently gained interest in the field of tissue engineering as they inherently possess an interconnected macroporous structure. Considered to be suitable for scaffold cryogel fabrication, methacrylated gelatin (GelMA) is a modified form of gelatin valued for its ability to retain cell adhesion site. Bioglass nanoparticles have also attracted attention in the field due to their osteoinductive and osteoconductive behavior. Here, we prepare methacrylated gelatin cryogel with varying concentration of bioglass nanoparticles to study its potential for bone regeneration. We demonstrate that an increase in bioglass concentration in cryogel leads to improved mechanical property and augmented osteogenic differentiation of mesenchymal cells during in vitro testing. Furthermore, in vivo testing in mice cranial defect model shows that highest concentration of bioglass nanoparticles $(2.5 w / w \%)$ incorporated in GelMA cryogel induces the most bone formation compared to the other tested groups, as studied by micro-CT and histology. The in vitro and in vivo results highlight the potential of bioglass nanoparticles incorporated in GelMA cryogel for bone regeneration.
\end{abstract}

Keywords: methacrylated gelatin; bioglass; hydrogel; cryogel; bone tissue engineering

\section{Introduction}

Bone regeneration following surgical removal of bone and injuries from sports, trauma, and disease is a challenging obstacle in clinical treatment because it can easily change course and impair the patient's quality of life. To augment bone regeneration, autografts and allografts are widely used to treat bone defects [1,2], and they are often applied clinically via the Masquelet technique [3] and the Reamer-Irrigator-Aspirator system [4], either independently or in combination. Although using bone grafts during these procedures possess desirable attributes, such as molecular cues, osteogenic cells, and niche for bone regrowth, retrieving these bone grafts still requires invasive and possibly fatal surgeries [5]. Using allografts could compensate for morbidity, but there is the possibility of transferring diseases from the donors [1,6]. In this aspect, application of synthetic biomaterial-based 
scaffold designed to emulate native bone structure is one of the most viable options for clinicians [7-14]. An effective biomaterial-based scaffold must be biocompatible and biodegradable while possessing adequate mechanical strength, highly interconnected pores, and optimal pore size [10,15]. As a type of scaffold that fulfills these criteria, cryogel-based scaffolds are being studied. Due to its highly interconnected and macroporous structure, cryogels have been investigated as a proper candidate for transportation of cells [16,17].

Materials for cryogel scaffolds vary greatly depending on their functions and characteristics. Synthetic polymers are a type of cryogel scaffold material that is often preferred over others. This includes polyacrylamide [18] and poly(vinyl alcohol) (PVA) [19] because their degradation rates can be manipulated. However, they are mostly biologically inert and lack cell binding moieties. For this reason, studies that develop new scaffolds focus on biological moieties, such as naturally derived polymers [16,20-23]. Among the various natural polymers, a collagen derivative called gelatin has favorable biological characteristics, such as the Arg-Gly-Asp (RGD) sequence. Having the RGD sequence present in scaffolds is valuable as it promotes cell adhesion, cell migration, and differentiation and helps to formulate extracellular matrix (ECM) similar to that of the bone $[24,25]$. Unfortunately, unmodified gelatin hydrogel lacks mechanical integrity, so many strategies are employed to prepare a mechanically stable hydrogel. One strategy is to add chemical moieties, such as furan [26,27], methacrylate [28], and others, to not only increase mechanical stiffness but also prepare photocrosslinked gelatin hydrogels $[29,30]$. There are a plethora of chemical moieties available today. However, methacrylation of gelatin (GelMA) has been widely studied as a photopolymerizable hydrogel because the mechanical property and porosity of GelMA-based scaffold can be controlled by varying the degree of methacrylic group substitution during the GelMA synthesis [24]. Nonetheless, using solely methacrylated gelatin in scaffolds is insufficient to induce osteogenic differentiation in stem cells.

Bioglass $\left(\mathrm{SiO}_{2}-\mathrm{CaO}-\mathrm{P}_{2} \mathrm{O}_{5}\right)$, like other calcium phosphates, has mustered attention in bone tissue engineering due to its osteoinductivity, biocompatibility, and ability to form strong bonds with bone and soft tissues [31,32]. The $\mathrm{Si}^{4+}$ and $\mathrm{Ca}^{2+}$ ions in bioglass have notable influence over cell differentiation and regulation of the cell cycle, making them vital, desirable ions for scaffold fabrication [33-35]. Moreover, bioglass can strongly bond with host tissue via formation of hydroxyapatite on its surface through surface chemistry under physiochemical conditions $[10,36]$. However, bioglass cannot be used alone as implants because it is too fragile; instead, it can be amalgamated with biopolymers to create composite scaffolds that possess bioactivity and plasticity [37]. Qu et al. suggested one solution for bioglass, which involved combining gelatin and bioglass hybrid scaffolds for the odontogenic differentiation of human dental pulp stem cells [38].

In this study, we investigated the bioactivity of nanobioglass on bone regeneration by fabricating bioglass-embedded methacrylated gelatin-based cryogel. To the best of our knowledge, there has been no prior report on methacrylated gelatin-based cryogel with bioglass-which would bring together the synergistic effect of cryogel, ECM for cell proliferation and host cell infiltration [16,39,40], and bioglass as a bioceramic - for enhancement of mineralization and osteogenic differentiation. We evaluated the mechanical strength, internal structure, cytotoxicity, and osteogenic differentiation ability and further carried out bone regeneration study in mouse cranial defect model. Herein, we demonstrate that nanobioglass-embedded GelMA cryogel induces osteogenic differentiation of human tonsil-derived stem cells (hTMSCs) by observing upregulation of osteogenic genes, calcium deposition, and enhanced bone regeneration in vivo study (Figure 1). 


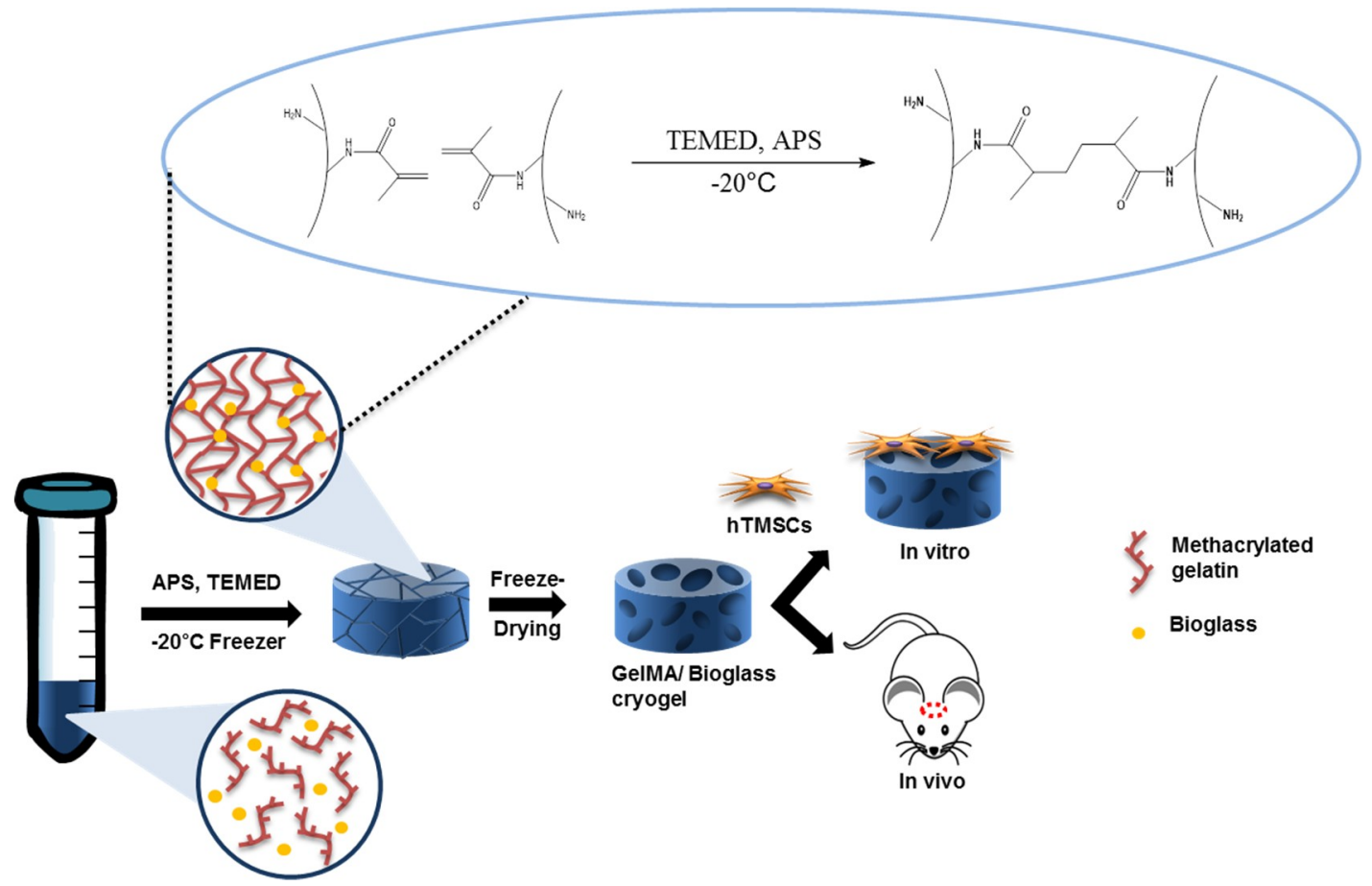

Figure 1. Overall scheme of the nanobioglass-embedded methacrylated gelatin (GelMA) cryogel experiment.

\section{Materials and Methods}

\subsection{Synthesis of Methacrylated Gelatin}

GelMA was synthesized by first dissolving type A porcine skin gelatin (Sigma-Aldrich, St. Louis, MO, USA) into Dulbecco's phosphate buffer saline (DPBS; Sigma-Aldrich, St. Louis, MO, USA) at $60{ }^{\circ} \mathrm{C}$ for $1 \mathrm{~h}$ to reach $10 \%(w / v)$ uniform solution [24,41]. An $8 \%(v / v)$ of methacrylic anhydride (Sigma-Aldrich, St. Louis, MO, USA) was then added to $10 \%(w / v)$ gelatin solution at a rate of $0.5 \mathrm{~mL} / \mathrm{min}$ under stirred condition and reacted for $3 \mathrm{~h}$ at $50{ }^{\circ} \mathrm{C}$. The resulting solution was $5 \times$-diluted with warm Dulbecco's phosphate buffer saline (Gibco, Waltham, MA, USA) and dialyzed using 12-14 kDa cutoff dialysis tube (Sigma-Aldrich, St. Louis, MO, USA) in water for 7 days at $40{ }^{\circ} \mathrm{C}$. The dialyzed solution was placed at $-80{ }^{\circ} \mathrm{C}$ for a day and lyophilized for another 7 days. After lyophilization, white, foam-type sponge was collected and stored at $-20^{\circ} \mathrm{C}$ for further use.

\subsection{Preparation of Nanobioglass}

Nanobioglass $\left(\mathrm{SiO}_{2}: \mathrm{CaO}: \mathrm{P}_{2} \mathrm{O}_{5}(\mathrm{~mol})=55: 40: 5\right)$ was prepared by the following protocol [42], with modifications. Briefly, $9.826 \mathrm{~mL}$ of tetraethyl orthosilicate (TEOS) diluted in $60 \mathrm{~mL}$ of EtOH was added to $120 \mathrm{~mL}$ of $\mathrm{Ca}\left(\mathrm{NO}_{3}\right)_{2} \cdot 4 \mathrm{H}_{2} \mathrm{O}$ solution $(270 \mathrm{mM})$. The $\mathrm{pH}$ of the solution was adjusted to $1-2$ with citric acid, and the reaction mixture was stirred vigorously for $12 \mathrm{~h}$. Homogeneous solution was added dropwise to $1500 \mathrm{~mL}$ of ammonium dibasic phosphate solution (5.44 mM). During this step, the $\mathrm{pH}$ of the solution was maintained at 11 using ammonium hydroxide. The mixture was stirred for $48 \mathrm{~h}$ and aged for $24 \mathrm{~h}$, following which the precipitate was separated by centrifugation. The precipitate was washed in $\mathrm{EtOH}$ and three times in water. The precipitate was suspended in $2 \%$ PEG-water solution and stirred for $30 \mathrm{~min}$. It was freeze-dried for $48 \mathrm{~h}$ and then sintered at $700{ }^{\circ} \mathrm{C}$ for $3 \mathrm{~h}$. The annealed bioglass was stored at room temperature until further use.

\subsection{Fabrication of GelMA-Bioglass Cryogel}

$10 \%(w / v)$ lyophilized GelMA was fully dissolved in DPBS (Sigma-Aldrich, St. Louis, MO, USA) at $60{ }^{\circ} \mathrm{C}$, and $0.5,1.5,2.5 \mathrm{wt} \%$ of bioglass were added to GelMA dissolved solution. For each 
solution, $0.5 \%(w / v)$ of ammonium persulfate (Sigma-Aldrich, St. Louis, MO, USA) and $0.25 \%(v / v)$ of $N, N, N^{\prime}, N^{\prime}$-tetramethylethylenediamine (Sigma-Aldrich, St. Louis, MO, USA) were added to initiate polymerization. Then, the solutions were pipetted to $200 \mu \mathrm{L}$ mold (cylindrical shape-diameter: $8 \mathrm{~mm}$ and height: $3 \mathrm{~mm}$ ) and placed at $-20^{\circ} \mathrm{C}$ for $24 \mathrm{~h}$ to slow down polymerization reaction while maximizing ice crystal fragments for larger pores. After gelation, ice fragments were removed via lyophilization, and cryogels were obtained. Cryogels were stored at $-80^{\circ} \mathrm{C}$ for further use.

\subsection{Swelling Ratio and Mechanical Property of Scaffold}

Swelling ratio test was performed to investigate water retention of cryogels according to bioglass concentration. For swelling tests, dry weights of each cryogel were measured and transferred to DPBS (Sigma-Aldrich, St. Louis, MO, USA) for a day to swell. After $24 \mathrm{~h}$, cryogels in DPBS were collected, and swelling weights of each cryogels were measured. The average swelling ratios of cryogels were calculated based on the following equation:

Swelling ratio $=\frac{W_{s}}{W_{d}}$, where $W_{s}$ is the swell weight of cryogels and $W_{d}$ is dried weight of cryogels.

Cryogels were swollen in DPBS for $24 \mathrm{~h}$ and tested for Young's modulus using the universal testing machine (Universal testing machine, EZ-SX, Shimadzu, Kyoto, Japan). Gels were compressed with the loading rate of $1 \mathrm{~mm} / \mathrm{min}$. The result was obtained by the stress-strain curve, and Young's modulus was calculated by the measurement of the slope linearly increased in the region of the stress-strain curve. The dataset was then analyzed using the equation:

Young's modulus $=\frac{\sigma}{\varepsilon}$, where $\sigma$ represents stress and $\varepsilon$ represents strains.

\subsection{Degradation by Collagenase}

Degradation rates of $10 \%(w / v)$ GelMA cryogels, GelMA- $0.5 \%(w / v)$ bioglass cryogels, GelMA-1.5\% $(w / v)$ bioglass cryogels, and GelMA-2.5\% $(w / v)$ bioglass cryogels were measured by placing them in 1 unit/mL of collagenase II solution (Worthington Biochemical). Samples were incubated in $37^{\circ} \mathrm{C}$, and old collagenase solutions were replaced with new collagenase solutions every day. Cryogels were removed from the collagenase solutions, and water on the surface of cryogels was removed before swollen weights of cryogel were measured at a time point.

\subsection{Ion Release Analysis}

Bioglass powder was autoclaved before measuring ion release level to remove any contaminants. Then, GelMA cryogels, GelMA- $0.5 \%$ bioglass cryogels, GelMA-1.5\% bioglass cryogels, and GelMA-2.5\% bioglass cryogels were fabricated $(n=3)$ and placed at 24 well plates and filled with $1 \mathrm{~mL}$ of simulated body fluid solution containing $58.43 \mathrm{~g}$ of $\mathrm{NaCl}, 2.77 \mathrm{~g}$ of $\mathrm{CaCl}_{2}$, and $1.39 \mathrm{~g}$ of $\mathrm{NaH}_{2} \mathrm{PO}_{4} \cdot \mathrm{H}_{2} \mathrm{O}$ (all chemicals from Sigma-Aldrich, St. Louis, MO, USA) in $1 \mathrm{~L}$ of deionized water (Sigma-Aldrich, St. Louis, MO, USA) as prepared. The solution was collected at day 1, 3, 5, and 7 and centrifuged at $4000 \mathrm{rpm}$ for $30 \mathrm{~min}$. Solutions were then filtered using $200 \mathrm{~nm}$ pore sizes of syringe membrane (Acrodisc ${ }^{\circledR}$ ) after samples were collected. Ion release rate of $\mathrm{Ca}^{2+}, \mathrm{Si}^{4+}$, and $\mathrm{P}^{3+}$ ions were measured with inductively coupled plasma atomic emission spectrometer (ICP-AES, Optima 8300, PerkinElmer, Waltham, MA, USA). To measure ion release rates of bioglass-embedded cryogels in deionized water, the same protocol was used.

\subsection{Scanning Electron Microscopy}

Internal structures of cryogels with different concentration of bioglass were observed via scanning electron microscopy (FE-SEM, JSM-6701F, JEOL, Tokyo, Japan). Cross sections of cryogels were fixed on mounts and coated with platinum at $20 \mathrm{~mA}$ for $100 \mathrm{~s}$. Then, internal structures were analyzed by Field emission electron microscopy (FE-SEM; JSM-6701F, JEOL, Tokyo, Japan). 


\subsection{Cell Cultures}

Human tonsil-derived mesenchymal stem cells were isolated from tonsillar tissue, which were provided by the Department of Otorhinolaryngology-Head and Neck Surgery, Seoul National University Hospital (Seoul, Korea) with prior consent. The Institutional Review Board (IRB) of Seoul National University Hospital approved this study. For proliferation, hTMSCs were cultured in general medium - 10\% fetal bovine serum (Biowest), 1\% L-glutamine (200 mM) (Sigma), $1 \%$ penicillin/streptomycin (10,000 U/mL) (Gibco), and 1\% antibiotic-antimycotic (100X; 15240062) (Gibco) in Dulbecco's modified Eagle's medium (Gibco). The culture medium was changed every other day.

\subsection{Cell Viability}

Cell viability was observed via Live/Dead viability kit (InvitrogenTM, Waltham, MA, USA). $5 \times 10^{5}$ cells of hTMSCs were seeded per cryogels and were incubated for $24 \mathrm{~h}$. After $24 \mathrm{~h}$, cryogels were washed with DPBS three times and $1 \mathrm{~mL}$ of DPBS, including $2 \mu \mathrm{L}$ calcein AM and $1 \mu \mathrm{L}$ ethidium homodimer-1, was added to each cryogel. Cryogels were incubated for $30 \mathrm{~min}$ and was measured by confocal microscope (Confocal Laser Scanning Microscope, LSM 720, Carl Zeiss, Oberkochen, Germany)

\subsection{In Vitro Osteogenic Differentiation}

hTMSCs were cultured in a 24-well plate until cells were $100 \%$ confluent. Then, cells were treated with osteogenic medium, the solution of $10 \mathrm{mM}$ glycerol-2-phosphate (Sigma), 1\% of 2-Phospho-L-ascorbic acid (Sigma), 1\% dexamethasone (Sigma), 10\% fetal bovine serum (Biowest), and $1 \%$ penicillin/streptomycin $(10,000 \mathrm{U} / \mathrm{mL})(\mathrm{Gibco})$ in Dulbecco's modified Eagle's medium. For bioglass-treated groups, osteogenic medium with $0.5 \%, 1.5 \%$, and $2.5 \%$ bioglass concentration was used. The culture medium was changed every other day.

\subsection{Real Time-PCR}

RNAs were extracted from the cell-laden GelMA and GelMA-bioglass cryogel $(n=3)$ with Trizol (Life Technology, Waltham, MA, USA). The concentration of RNA that was extracted was measured by NanoDrop spectrometer (ND-2000; NanoDrop Technologies) and reverse-transcribed into cDNA using TOPscriptTMReverse Transcriptase Kit (Enzynomics). Real time-PCR was performed using ABI StepOnePlusTM real-time PCR system (Applied Biosystems). cDNA samples were analyzed for relative gene expression of GAPDH, OCN, Collagen I, and Runx2 when GAPDH was used as a house-keeping gene. Relative gene expressions of interests were calculated using $-2^{\Delta \Delta C t}$ method. Primer sequences that were used in RT-PCR were: GAPDH (Forward: $5^{\prime}$-CGC TCT CTG CTC CTC CTG TT-3', Reverse: 5'-CCA TGG TGT CTG AGC GAT GT-3'), OCN (Forward: 5'-GCC TTT GTG TCC AAG C-3', Reverse: 5'-GGA CCC CAC ATC CAT AG-3'), Collagen I (Forward: 5'-GTC ACC CAC CGA CCA AGA AAC C-3', Reverse: 5'-AAG TCC AGG CTG TCC AGG GAT G-3'), Runx2 (Forward: 5'-ACT GGG CCC TTT TTC AGA-3', Reverse: 5'-GCG GAA GCA TTC TGG AA-3').

\subsection{Alizarin Red Staining}

After 21 days of differentiation, cells were washed with DPBS twice and fixed using 4\% paraformaldehyde for $15 \mathrm{~min}$ at room temperature. Fixed cells were stained with $2 \%$ alizarin red staining solution for $20 \mathrm{~min}$ and washed three times with distilled water for $5 \mathrm{~min}$ each.

\subsection{Calvarial Defect Surgical Procedure}

All experiments were carried out in accordance with the Guide for the Care and Use of Laboratory Animals by Seoul National University (Approval No. SNU-141229-3-6). All operations were performed under Zoletil 50 (Virbac, Carros, France) and Rompuninj (Bayer, Leverkusen, Germany) anesthesia to 
minimize animal suffering. Twelve female balb-C mice (OrientBio Co., Seoul, Korea) were used for calvarial defects. Mice were caged and handled in a sterile room at $22{ }^{\circ} \mathrm{C}$ and $50 \%$ humidity with $12 \mathrm{~h}$ of light and dark cycles. Before calvarial defect surgery, mice were under anesthesia via intraperitoneal injection. Under anesthesia, incision was made on forehead, and 4-mm diameter of calvarial defect was performed using a trephine bur attached to hand drilling machine. Cryogels were transplanted to defected sites, and mice were collected after eight weeks of transplantation.

\subsection{Microcomputed Tomography Analysis}

Defected sites of mice were collected and fixed with $4 \%$ paraformaldehyde solution. Images of surgical sites were obtained using Skyscan 1172 at $59 \mathrm{kV}$ of operation source voltage, $167 \mu \mathrm{A}$ of source current, and $40 \mathrm{~ms}$ of an exposure time. The projected images were reconstructed into 3D images for further analysis using ReCon MicroCT from Skyscan.

\subsection{Histological Analysis}

After fixing defected area and surrounding tissue of skulls in $4 \%$ paraformaldehyde solution for $24 \mathrm{~h}$, skulls were decalcified using 14\% ethylene diaminetetraacetic acid (EDTA) at pH 7.4 for 4 days. Then, skulls were embedded in paraffin solutions and longitudinally sectioned at a thickness of $5 \mu \mathrm{m}$. Sectioned samples were deparaffinated using xylene solution and gradually washed with tap water. Samples were stained with H\&E staining and Masson's trichrome (MTC) staining and analyzed using light microscope (Olympus, Tokyo, Japan).

\subsection{Statistical Analysis}

Quantitative data in this paper are presented in mean \pm standard deviation. The statistical significance was determined using one-way analysis of variance (ANOVA) with ${ }^{*} p<0.05,{ }^{* *} p<0.001$, and ${ }^{* * *} p<0.0001$.

\section{Results}

\subsection{Synthesis of Methacrylated Gelatin and Bioglass}

Gelatin methacrylate was synthesized to provide cross-linking sites to conventional gelatin because it required glutaraldehyde, which was reported to be cytotoxic for forming permanent chemical cross-linking. Methacrylation of gelatin was confirmed using ${ }^{1} \mathrm{H} N \mathrm{NR}$, as the characteristic peaks of acrylic hydrogen were present at 5.3 and $5.5 \mathrm{ppm}$ (Figure S1). Then, bioglass nanoparticles (BGN) were prepared by sol-gel synthesis route (Figure 2a). The size of bioglass was measured using scanning electron microscopy (SEM). As shown in Figure $2 b$, the morphology of synthesized bioglass particles was round, amorphous, and around $53.83 \pm 13.01 \mathrm{~nm}$ in size. The Fourier-transform infrared spectroscopy (FT-IR) was used to further analyze the structure of bioglass (Figure 2c). The FT-IR spectrum showed characteristic bending vibration of phosphate group peaks at 561 and $603 \mathrm{~cm}^{-1}$ and Si-O-Si stretching band at $1080 \mathrm{~cm}^{-1}$. After synthesizing BGN, its bioactivity postimplantation was tested. BGN was immersed for 14 days in simulated body fluid (SBF) solution and compared with prepared BGN by X-ray powder diffraction (XRD). As shown in Figure 2d, same hydroxyapatite peaks as those noted by Constantz et al. and Ishikawa et al. were presented in BGN soaked in SBF solution, confirming the bioactivity of synthesized BGN $[43,44]$. 
a
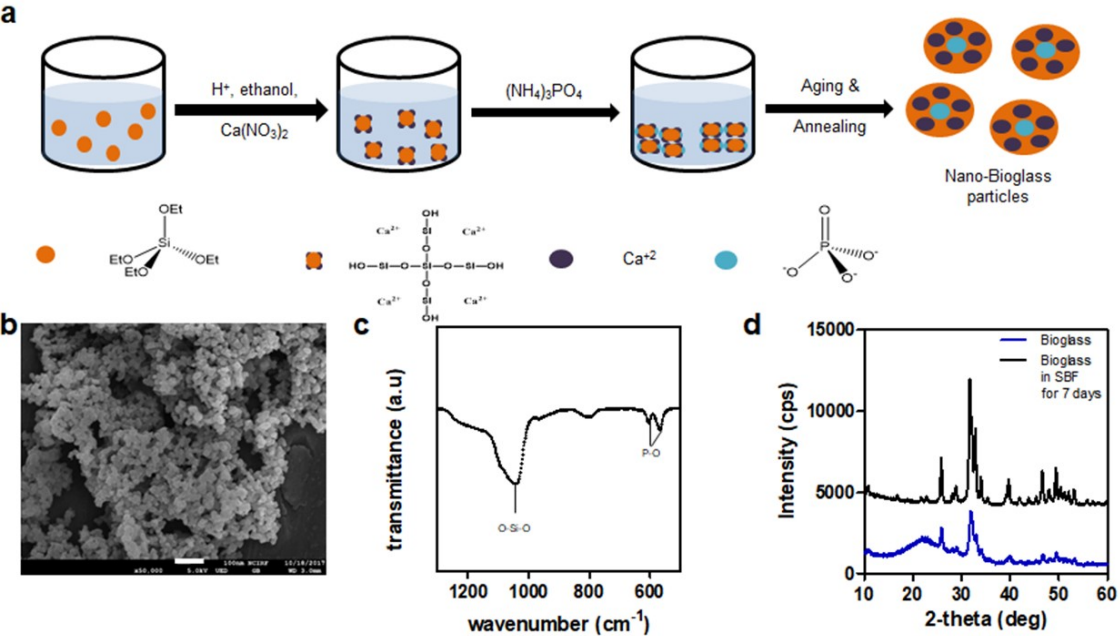

Figure 2. Bioglass characterization (a) Schematic representation of nanobioglass synthesis; (b) SEM images of bioglass nanoparticle; scale bar $=200 \mathrm{~nm}$; (c) FTIR spectrum; (d) XRD of bioglass nanoparticle and bioglass nanoparticle immersed in simulated body fluid (SBF) for seven days.

\subsection{Characterization of Bioglass-Embedded Methacrylated Gelatin Cryogel}

GelMA cryogels were synthesized via chemically cross-linking GelMA solution using ammonium persulfate and $N, N, N^{\prime}, N^{\prime}$-tetramethylethylenediamine with various concentration of BGN (Figure 3a). Then, the swelling ratio of BGN-embedded GelMA cryogels was measured. As shown in Figure 3b, the descending trend of swelling ratio was observed from 8.30 to 6.37 as the concentration of bioglass in cryogels was increased. Furthermore, Young's modulus of all groups was measured through analyzing stress vs. strain graph from the mechanical testing. As expected, Young's modulus of cryogel was increased as the concentration of BGN also augmented from $84.67 \pm 16.17$ to $178 \pm 47.70 \mathrm{kPa}$ (Figure 3c).

a

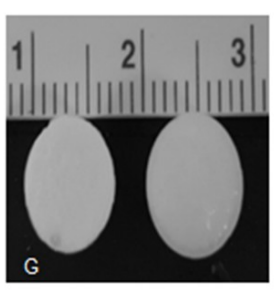

b

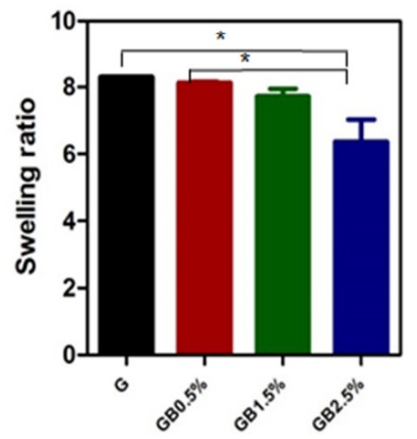

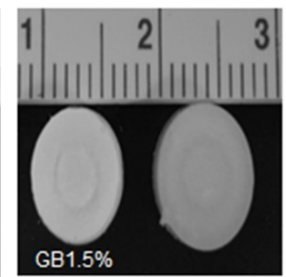

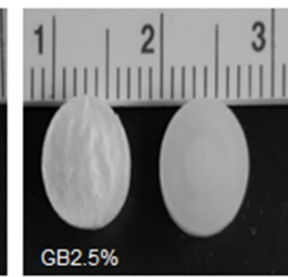

C

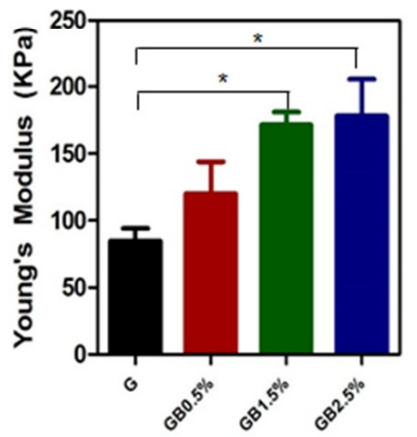

Figure 3. Scaffold characterization (a) Gross images of dried and swollen cryogels; (b) Swelling ratio; (c) Young's modulus of cryogels $(\mathrm{n}=3, * p<0.05)$. Error bars indicate SD. G represents GelMA cryogel, and GB represents bioglass-incorporated GelMA cryogel with the concentration of bioglass noted. 
The degradation rates of cryogel were tested for their dependency on the bioglass concentration in the presence of collagenase II. Collagenase II was widely used to test degradation times of GelMA-based cryogel $[41,45]$. The degradation time was not significantly different between the control group and the experimental group due to the relatively low concentration of BGN compared to that of GelMA (Figure S2). The remaining mass percentage after degrading GelMA cryogel for 7 days was $49.80 \pm 2.91 \%$, while remaining mass percentages of cryogels for $0.5 \%, 1.5 \%$, and $2.5 \%$ BGN were $66.33 \pm 8.73 \%, 60.48 \pm 2.69 \%$, and $64.02 \pm 6.11 \%$, respectively.

Because the increase in Young's modulus seemed to be linked to the increase in bioglass concentration incorporated to cryogel, internal structures of cryogels were observed to ensure that the differences in porosity between experimental and control groups were negligible. The internal structures of BGN-embedded GelMA cryogels were observed using SEM (Figure 4a). Then, the SEM images of lyophilized BGN-embedded GelMA cryogels were analyzed further with ImageJ for average pore area. As shown in Figure $4 b$, there was no significant difference among the groups with different concentration of BGN. Since BGN was physically mixed with GelMA solution when cryogel fabrication was performed, both the experimental groups and the control group possessed similar internal structures. Furthermore, cell permeabilities of scaffolds were examined via seeding green fluorescent protein (GFP)-tagged HELA cells on GelMA and GelMA-bioglass cryogels and using confocal microscopy after $24 \mathrm{~h}$ (Figure 4c). Then, in order to quantify the cell permeabilities of scaffolds, the number of cells was counted and, expectedly, all cryogel groups had uniform cell permeability (Figure $4 \mathrm{~d})$.
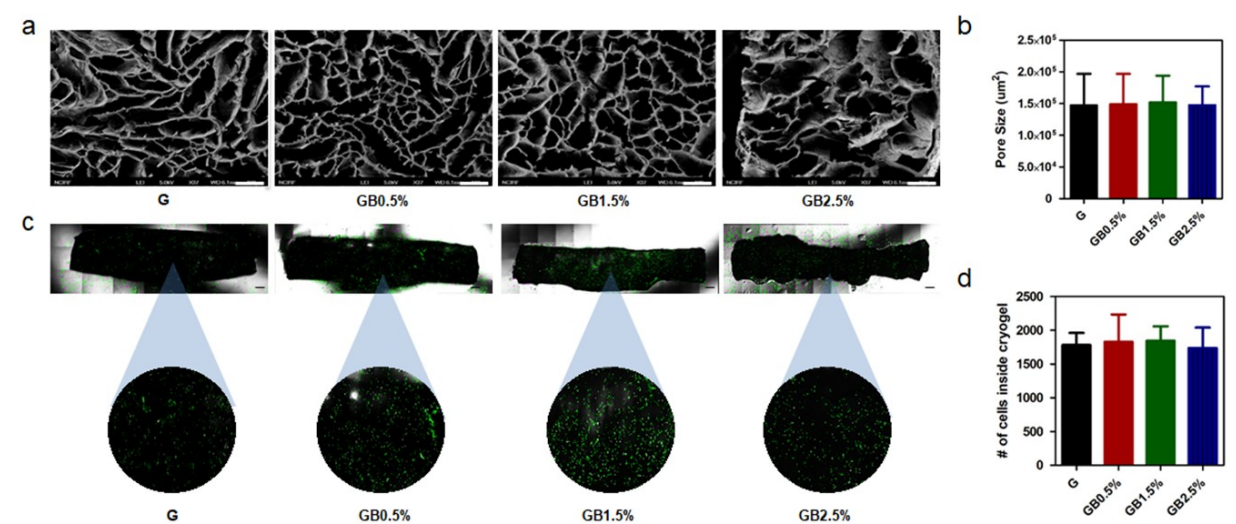

Figure 4. Internal structure of cryogels (a) Cross-sectional view of cryogels, as studied by FE-SEM; scale bar $=400 \mu \mathrm{m}$; (b) Average pore area of lyophilized cryogel with different bioglass concentration; error bars indicate SD ( $\mathrm{n}=3$ ); (c) cell permeability in G, GB0.5\%, GB1.5\%, and GB2.5\% cryogels; scale bar $=500 \mu \mathrm{m}$; (d) Number of cells inside the cryogel; error bars indicate SD (n=3).

\subsection{Hydroxyapatite Formation in SBF Solution}

Various studies have confirmed the bioactivity of intact bioglass nanoparticle; yet, bioactivities of cryogels in which BGN are embedded have not been emphasized. First, in order to measure $\mathrm{Si}^{4+}$ and $\mathrm{Ca}^{2+}$ ion release from bioglass-embedded cryogels, BGN-embedded cryogels were incubated in deionized water for 7 days and measured using inductively coupled plasma atomic emission spectrometer. As shown in Figure 5a, as the concentration of nanobioglass in cryogel increased, released amount of $\mathrm{Si}^{4+}$ and $\mathrm{Ca}^{2+}$ ion increased as well. To measure the bioactivity, BGN-embedded cryogels were incubated in SBF solution for 7 days, and phosphorus and silicon ion release kinetics were measured. Based on the incubation time, the amount of released silicon ions increased as the amount of released phosphorus ions decreased (Figure $5 b$ ). 
a
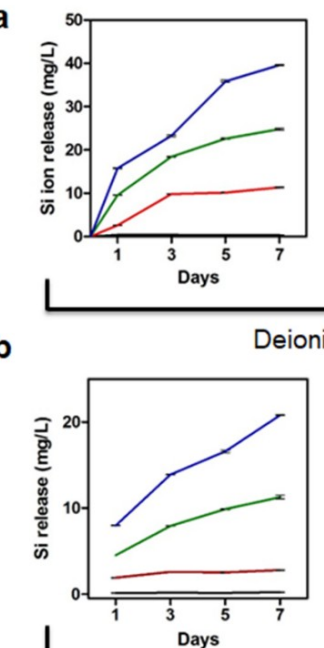
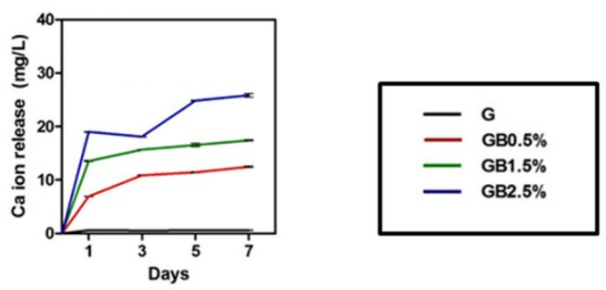

Days
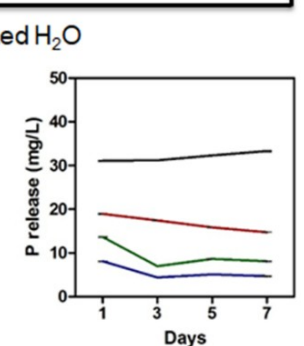

Simulated body fluid

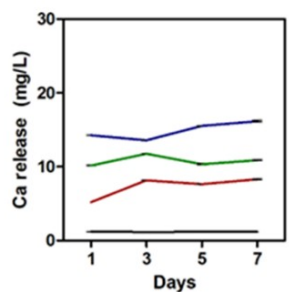

Days

Figure 5. Ion release analysis. Ion dissolution rates of cryogels tested for period of seven days in (a) deionized water and (b) simulated body fluid; error bars indicate SD.

After seven days of incubation, internal structures of each group were observed through SEM for possible hydroxyapatite formation. As shown in Figure $5 \mathrm{a}$, were able to find formed hydroxyapatite particles from SEM image (Figure 6a). Furthermore, calcium to phosphate ratio on the surfaces of cryogels was calculated to be 1.63 , which was very close to the textbook value of calcium to phosphorus ratio of hydroxyapatite (Figure 6 b). Then, the relationship between the formed hydroxyapatite and concentration of BGN was analyzed with XRD. Figure $6 c$ shows that the intensity of hydroxyapatite concentration increased as the concentration of BGN increased. Among the groups, $2.5 \%$ BGN-embedded cryogel resulted in the highest intensity.

a
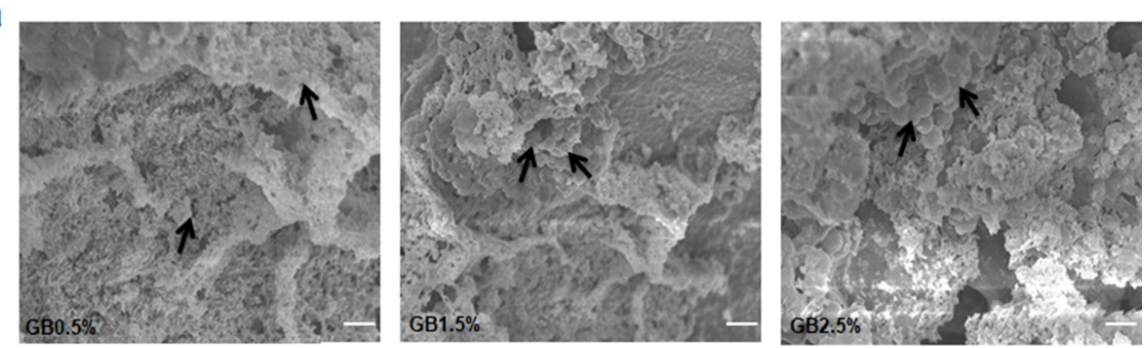

b
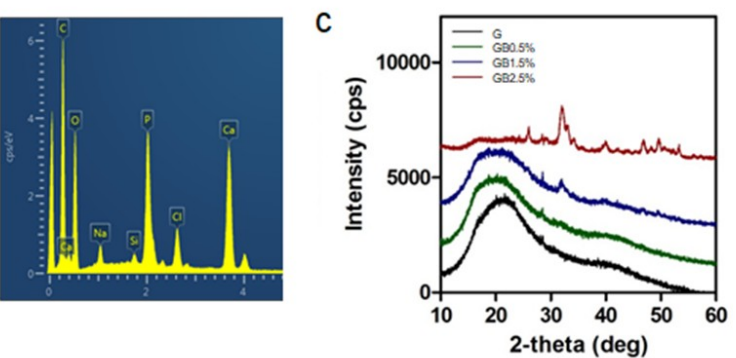

Figure 6. Bioactivity of bioglass (a) SEM images of GB0.5\%, GB1.5\%, and GB2.5\% cryogels after immersing in SBF solution for seven days. Black arrow represents formed hydroxyapatite; scale bar $=1 \mu \mathrm{m}$; (b) EDS mapping of GB2.5\%; (c) XRD of G, GB0.5\%, GB1.5\%, and GB2.5\% cryogels. 


\subsection{Cell Viability Analysis}

Cell viability tests were performed to investigate the cytotoxicity of groups for further cellular responses. Human tonsil-derived mesenchymal stem cells were seeded on BGN-embedded cryogels and after $24 \mathrm{~h}$ of incubation, live/dead viability test was proceeded. Fluorescence images of each group after incubating (hTMSCs) on cryogels for $24 \mathrm{~h}$ were observed (Figure 7a). Then, cell viabilities of each group were calculated based on fluorescence images. The percentage of cell viability was slightly decreased as the concentration of bioglass increased; however, all groups showed over $90 \%$ of cell viability (Figure 7b). For the seeding efficiency of hTMSCs on GelMA and bioglass nanoparticles incorporated cryogels, the percentage of seeding efficiency decreased as the concentration of bioglass increased (Figure 7c). This indicates that increase of bioglass concentration lead less cells to be seeded on the surface of GelMA. However, all groups showed over $30 \%$ of cell seeding efficiency.
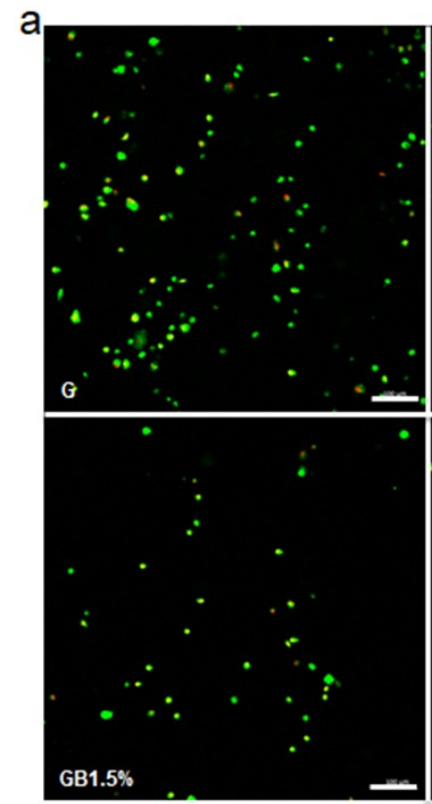
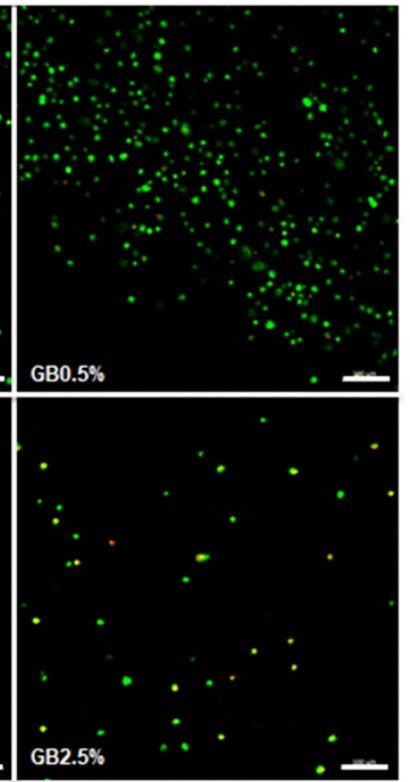

b

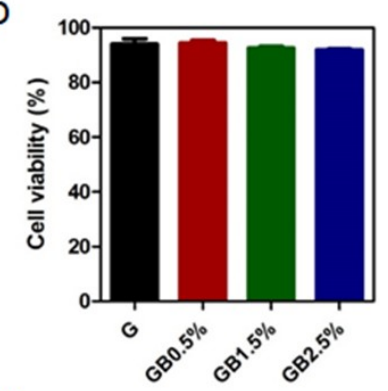

C

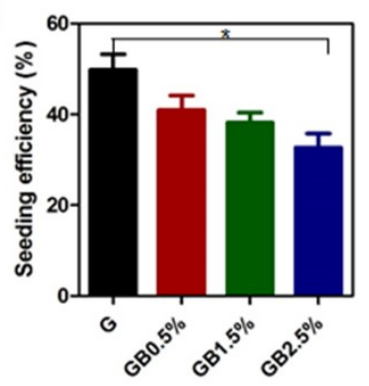

Figure 7. Cell viability test: (a) Fluorescence images of live/dead staining of human tonsil-derived stem cells (hTMSCs) cultured for $24 \mathrm{~h}$ on GelMA and bioglass nanoparticles-incorporated cryogels; scale bar = $100 \mu \mathrm{m}$; (b) cell viability as quantified by live/dead assay using ImageJ; error bars indicate SD ( $\mathrm{n}=3$ ); (c) seeding efficiency of hTMSCs that were seeded on GelMA and bioglass nanoparticles-incorporated cryogels; error bars indicate SD $(n=3)$.

\subsection{Enhanced Osteogenic Responses on hTMSCs on GelMA-Bioglass cryogel}

After confirming hydroxyapatite formation and cytotoxicity, osteogenic potential of BGN-embedded cryogels was verified by seeding hTMSCs on top of cryogels and culturing the cells with osteogenic medium for 7 and 14 days to measure relative osteogenic gene expression. On both day 7 and day 14, quantitative real-time PCR analysis of osteogenic markers confirmed that hTMSCs seeded on cryogels with higher concentration of bioglass (1.5\% and $2.5 \%$ of $\mathrm{BGN})$ augmented bone-related gene expressions compared to GelMA cryogel at day $14-7.84(1.5 \% \mathrm{BGN})$ and $13.13(2.5 \% \mathrm{BGN})$ fold increase in osteocalcin, $13.56(1.5 \% \mathrm{BGN})$ and $29.92(2.5 \% \mathrm{BGN})$ fold increase in collagen I, and $6.47(1.5 \% \mathrm{BGN})$ and 12.83 (2.5\% BGN) fold increase in Runx2 (Figure 8). However, the difference in gene expressions of GelMA cryogel and GelMA-0.5\% bioglass cryogel was not significant on day 7 and day 14 . 
a

Runx2

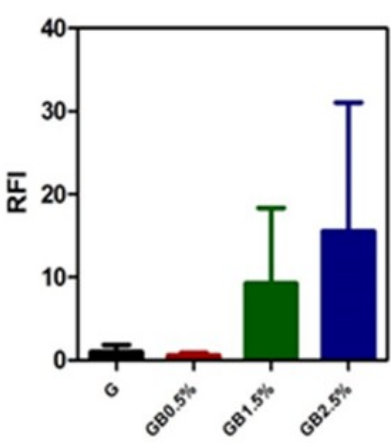

b

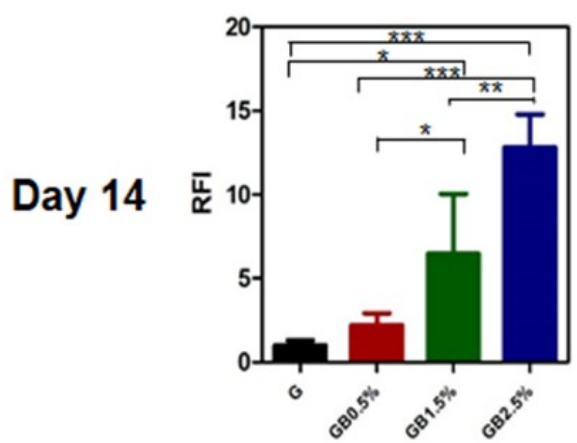

Col I

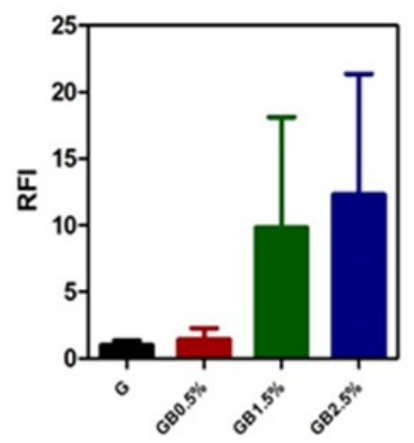

Col I

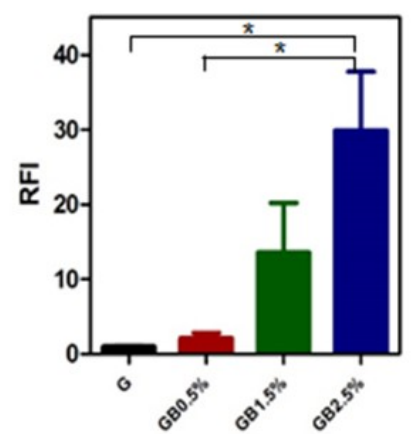

OCN

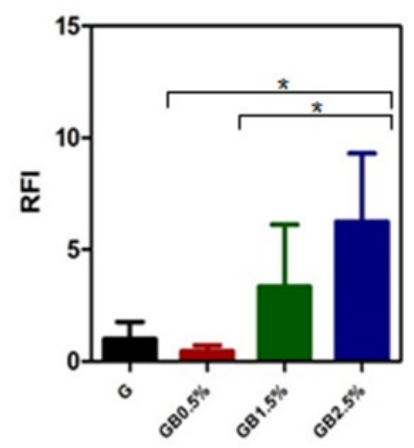

OCN

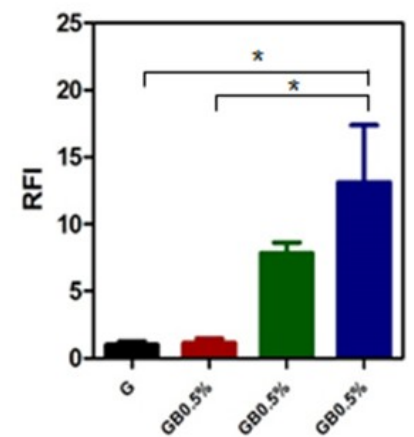

Figure 8. Relative osteogenic gene expression. Relative osteogenic expression of hTMSCs seeded on cryogels (a) at day $7,(\mathbf{b})$ at day $14\left(\mathrm{n}=3,{ }^{*} p<0.05,{ }^{* *} p<0.001,{ }^{* * *} p<0.0001\right)$; error bars indicate SD.

Further investigating cellular responses of hTMSCs, the cells were cultured on petri dishes in osteogenic medium with similar concentration of bioglass for 21 days. Then, the amount of calcium deposition of each sample was measured using alizarin red staining (Figure S3). The result was similar to that of quantitative real-time PCR - higher calcium deposition was observed as bioglass dosage increased.

\subsection{In Vivo Bone Regeneration after Implanting Bioglass-Embedded GelMA Cryogel}

To examine the optimal concentration of BGN embedded in GelMA cryogels for effective bone regeneration, in vivo studies were conducted. GelMA-bioglass cryogels were implanted to calvarial defect areas of balb/c mice. Then, bone regeneration of the defected areas was evaluated using microCT eight weeks after transplantation (Figure 9a). Corresponding to in vitro cell studies, bone volume/ total volume (BV/TV) of cryogels containing the highest bioglass concentration was 3.89-fold higher compared to the control group (Figure $9 b$ ). In addition, cell penetration on the scaffold was evaluated via histology. Histological analysis of H\&E staining and Masson's trichrome staining (MTC) showed that as the concentration of bioglass increased, more regenerated bone tissues along with collagen were found in the defect area where the nanobioglass-embedded cryogels were implanted (Figure 9c). Histological analysis and microCT confirmed that GelMA-2.5\% bioglass cryogel enhanced bone regeneration the most compared to other experimental groups. 
a
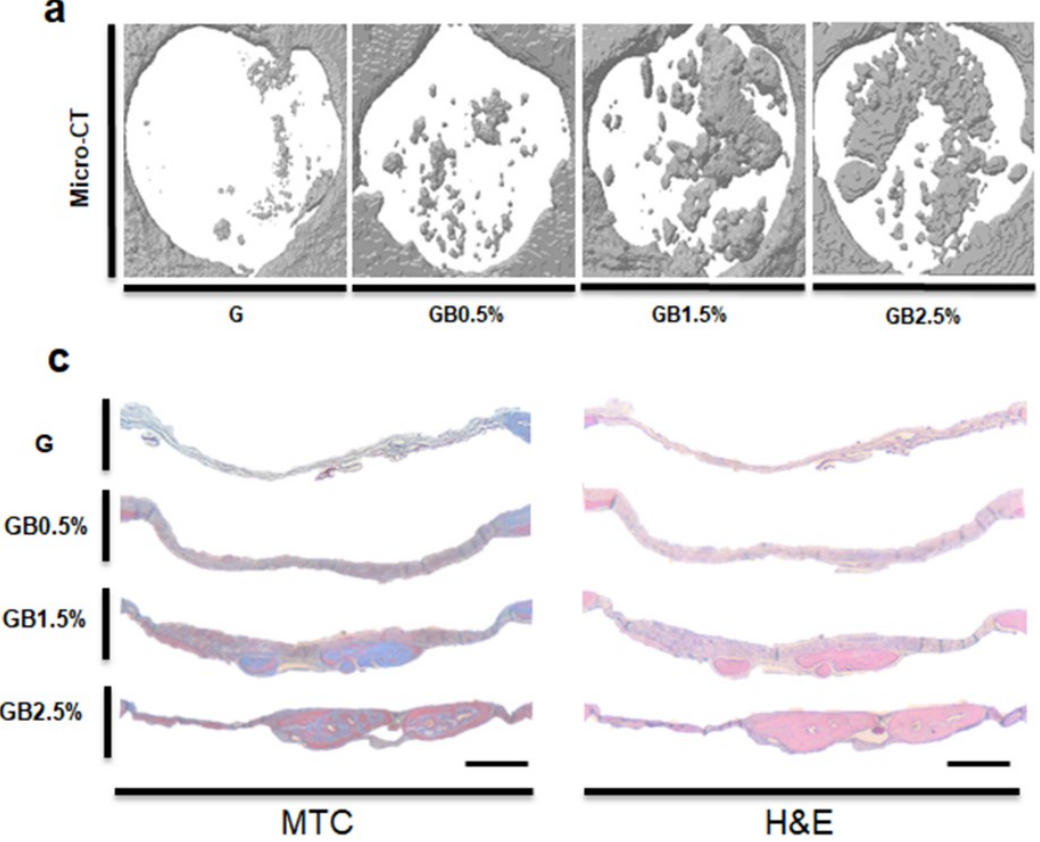

b

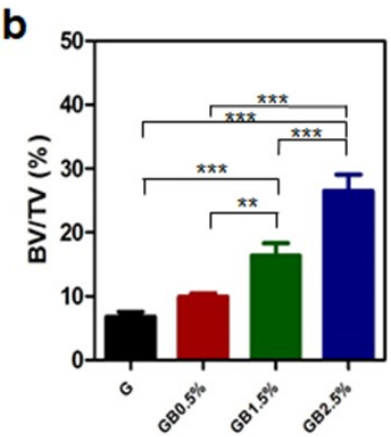

Figure 9. In vivo experiment. (a) microCT images of cranial defect (defect diameter $=4 \mathrm{~mm}$ ) and (b) normalized bone volume/ total volume (BV/TV) of defect after eight weeks of transplantation; error bars indicate SD $(n=3)$. (c) Histological analysis of Masson Trichrome and H\&E staining; scale bar $=500 \mu \mathrm{m}$.

\section{Discussion}

Synthetic calcium phosphate-based materials have been widely studied for regenerating defected bone area. Among them, bioglass is valued for its ability to enhance osteogenic differentiation by forming hydroxyapatite and releasing osteoinductive ions; various studies have demonstrated the invaluable effects of osteoinductive ions on bone regeneration process [46-50]. In addition to supplying calcium phosphate, providing extracellular matrix-like environment enhances osteoregeneration during the bone healing process [51,52]. Because it is capable of mimicking natural ECM and has a porous structure, cryogel is widely used in tissue engineering [53,54]. From this idea, we embedded bioglass into GelMA cryogels in an attempt to provide an osteogenic-friendly environment (Figure 1). Furthermore, the macroporous structure of GelMA would provide cancellous bone-like structure where host stem cells can migrate. A closer look at the microstructure of GelMA-based cryogel showed that the overall pore size was unaffected by the addition of bioglass (Figure 4a). However, physical adhesion between GelMA and bioglass may have contributed to the bioglass concentration-dependent reduction in swelling ratio and increase in mechanical properties of cryogel. Pluharova et al. have previously demonstrated that ion-dipole interaction persists between amide group and calcium ions [55]. Thus, this physical adhesion in combination with ion-dipole interactions from calcium ions from bioglass and amide groups in GelMA may have contributed to the overall physical characteristics of cryogels.

Mineralization of inorganic minerals plays an important role in maintaining bioactivities in body fluids $[56,57]$. The mechanism of surface chemistry and bioactivity of bioglass powder in SBF solution has been widely studied [58,59]. From the results obtained in this study via testing bioactivities of bioglass-embedded cryogels, formation of hydroxyapatite was observed via XRD. However, the ion concentration threshold seemed to be present according to XRD. The amount of mineral deposited was gradually increased with the concentration of bioglass until 1.5\% and sharp increase with $2.5 \%$ bioglass concentration (Figure 6c). This result suggested that the minimum amount of bioglass was required to trigger hydroxyapatite formation in early periods since the rate of hydroxyapatite formation is 
depended on presence of $\mathrm{Ca}^{2+}$ and $\mathrm{P}^{3+}$ ions. This result is similar to the findings of Hench et al. as the authors discovered that the rate of hydroxyapatite formation is depended on concentration of bioglass [60].

Ion release rates of $\mathrm{Si}^{4+}, \mathrm{Ca}^{2+}$, and $\mathrm{P}^{3+}$ ions from bioglass immersed in SBF solution revealed that $\mathrm{Si}^{4+}$ ions were released to form silanol, enhancing overall hydroxyapatite formation by forming apatite nuclei (Figure 5) [61]. After forming apatite nuclei, the saturation of $\mathrm{Ca}^{2+}$ ions was reached in the solution. Then, the hydroxyapatite layer was formed via recapturing and adsorbed $\mathrm{P}^{3+}$ ions, which were released to the solution on the apatite nuclei. Thus, the concentrations of $\mathrm{P}^{3+}$ ions decreased as time passed.

Furthermore, the mineralized surfaces of cryogels were measured via EDS mapping, and only the GelMA-2.5\% bioglass group showed apatite with $1.63 \mathrm{Ca}^{2+} / \mathrm{P}^{3+}$ ratio; this is similar to the theoretical $\mathrm{Ca}^{2+} / \mathrm{P}^{3+}$ value of 1.67 (Figure $6 \mathrm{~b}$ ). This result suggests a possible direct cryogel-bone bonding, which may increase the in vivo bone generation [62].

Osteogenic effects of bioglass-embedded GelMA cryogels on hTMSCs were measured using RT-PCR and alizarin red staining. In our studies, osteogenic genes-OCN, Runx2, and Col I-were further up-regulated according to the concentration of bioglass on day 7 and day 14 (Figure 8), and similar trend was observed when calcium deposition was measured after 21 days via alizarin red staining (Figure S3). Osteogenic differentiation of hTMSCs was enhanced due to ion dissolutions from bioglass in osteogenic medium since similar trend of $\mathrm{Ca}^{2+}$ and $\mathrm{Si}^{4+}$ ion release rates were observed according to bioglass dosage embedded in cryogel (Figures 5 and 8). Calcium ion released from bioglass enhanced mineralization, inducing guiding stem cells to osteoblasts [63]. Furthermore, S. Maeno et al. also supported that $\mathrm{Ca}^{2+}$ ion induces osteogenic differentiation in both monolayer and 3D culture [64]. Our study confirmed that osteogenic differentiation of hTMSCs is dependent on the concentration of bioglass incorporated in cryogel. $\mathrm{Si}^{4+}$ ion-a bioglass component-is well known to promote bone formation and calcification in the early stages, though high concentrations of $\mathrm{Si}^{4+}$ ion increase cytotoxicity. In our studies, large amounts of silicon ion had not been incorporated into bioglass; however, as expected, cryogel with the highest concentration of bioglass showed the most cytotoxicity among the groups (Figure $7 \mathrm{~b}$ ). All groups showed over $90 \%$ of cell viability, which suggests that although increased concentration of $\mathrm{Si}^{4+}$ leads to higher cytotoxicity, it would be safe to use for the concentration that was used in this study.

Based on in vitro results, cryogels were implanted for eight weeks and measured to examine if bone regeneration in a calvarial defect improved. As demonstrated by in vitro results, bioglass helped bone regeneration of defected area. According to microCT data, cryogels with the highest concentration of bioglass nanoparticles had the most bone healing compared to other cryogel groups (Figure 9). Furthermore, higher concentration of collagen was observed via Masson's trichrome staining and H\&E staining in the highest bioglass concentration group. In conclusion, bioglass has an osteoinductive effect in bone healing process.

\section{Conclusions}

From our study, we demonstrated that bioglass-incorporated GelMA cryogels effectively promoted bone healing. Tested concentrations of bioglass-embedded cryogel showed enhanced mechanical strength without affecting the porosity and cytotoxicity. Furthermore, it not only induced osteogenic differentiation of hTMSCs but was also bioactive, forming hydroxyapatite on its surface. Thus, by manipulating the dose-dependent nature of bioglass, bioglass-incorporated cryogel could be a potential candidate in clinical application for bone tissue engineering.

Supplementary Materials: The following are available online at http:/ /www.mdpi.com/2073-4360/10/8/914/s1, Figure S1: ${ }^{1} \mathrm{H}$ NMR of gelatin and methacrylated gelatin, Figure S2: Degradation rates of cryogel using collagenase II solution for 7 days, Figure S3: Alizarin red staining after 21 days.

Author Contributions: Conceptualization, S.K. and N.S.H.; Data curation, S.K. and S.S.L.; Formal analysis, S.K. and S.S.L.; Funding acquisition, N.S.H.; Investigation, S.K.; Methodology, S.K.; Project administration, S.K., 
S.S.L. and N.S.H.; Resources, N.S.H.; Supervision, S.K.K., R.J. and N.S.H.; Validation, S.S.L.; Visualization, S.K., S.S.L., S.H.L.K. and M.Y.N.; Writing-original draft, S.K.; Writing-review \& editing, S.S.L., A.S., J.K., S.H.L.K. and N.S.H.

Acknowledgments: This research is supported by National Research Foundation (NRF) grant funded by Ministry of Science and ICT of Korea (NRF-2017M3A9C6031786 and NRF-2017K1A3A1A19070731). The Institute of Engineering Research at Seoul National University provided research facilities for this work. A. Sivashanmugam acknowledges the Department of Science and Technology (DST, India) and National Research Foundation (NRF, Republic of Korea) for awarding "Indo Korea-Internship Programme-2016" (Award No. INT/ROK/IKRI-2/2016/dated on 9/5/2017) and Council of Scientific and Industrial Research (CSIR) for the financial support through Senior Research Fellowship (SRF Award No. 09/963 (0038)2K17-EMR-I).

Conflicts of Interest: The authors declare no conflict of interest.

\section{References}

1. Fillingham, Y.; Jacobs, J. Bone grafts and their substitutes. Bone Jt. J. 2016, 98-B, 6-9. [CrossRef] [PubMed]

2. Hofbauer, M.H.; Delmonte, R.J.; Scripps, M.L. Autogenous bone grafting. J. Foot Ankle Surg. 1996, 35, $386-390$. [CrossRef]

3. Giannoudis, P.V.; Faour, O.; Goff, T.; Kanakaris, N.; Dimitriou, R. Masquelet technique for the treatment of bone defects: Tips-tricks and future directions. Injury 2011, 42, 591-598. [CrossRef] [PubMed]

4. Cox, G.; Jones, E.; McGonagle, D.; Giannoudis, P.V. Reamer-irrigator-aspirator indications and clinical results: A systematic review. Int. Orthop. 2011, 35, 951-956. [CrossRef] [PubMed]

5. Jones, J.R.; Hench, L.L. Materials perspective-biomedical materials for new millennium: Perspective on the future. Mater. Sci. Technol. 2001, 17, 891-900. [CrossRef]

6. Betz, R.R. Limitations of autograft and allograft: New synthetic solutions. Orthopedics 2002, 25, s561-s570. [PubMed]

7. Pina, S.; Oliveira, J.M.; Reis, R.L. Natural-based nanocomposites for bone tissue engineering and regenerative medicine: A review. Adv. Mater. 2015, 27, 1143-1169. [CrossRef] [PubMed]

8. Venkatesan, J.; Bhatnagar, I.; Manivasagan, P.; Kang, K.H.; Kim, S.K. Alginate composites for bone tissue engineering: A review. Int J. Biol. Macromol. 2015, 72, 269-281. [CrossRef] [PubMed]

9. Cox, S.C.; Thornby, J.A.; Gibbons, G.J.; Williams, M.A.; Mallick, K.K. 3D printing of porous hydroxyapatite scaffolds intended for use in bone tissue engineering applications. Mater. Sci. Eng. C Mater. Biol. Appl. 2015, 47, 237-247. [CrossRef] [PubMed]

10. Bose, S.; Roy, M.; Bandyopadhyay, A. Recent advances in bone tissue engineering scaffolds. Trends Biotechnol. 2012, 30, 546-554. [CrossRef] [PubMed]

11. Kim, J.; Kim, H.D.; Park, J.; Lee, E.S.; Kim, E.; Lee, S.S.; Yang, J.K.; Lee, Y.S.; Hwang, N.S. Enhanced osteogenic commitment of murine mesenchymal stem cells on graphene oxide substrate. Biomater. Res. 2018, $22,1$. [CrossRef] [PubMed]

12. Gwak, G.H.; Choi, A.J.; Bae, Y.S.; Choi, H.J.; Oh, J.M. Electrophoretically prepared hybrid materials for biopolymer hydrogel and layered ceramic nanoparticles. Biomater. Res. 2016, 20, 1. [CrossRef] [PubMed]

13. Chen, C.; Bang, S.; Cho, Y.; Lee, S.; Lee, I.; Zhang, S.; Noh, I. Research trends in biomimetic medical materials for tissue engineering: $3 \mathrm{~d}$ bioprinting, surface modification, nano/micro-technology and clinical aspects in tissue engineering of cartilage and bone. Biomater. Res. 2016, 20, 10. [CrossRef] [PubMed]

14. Lee, E.S.; Kim, S.H.; Lee, H.; Hwang, N.S. Non-viral approaches for direct conversion into mesenchymal cell types: Potential application in tissue engineering. J. Biomed. Mater. Res. B Appl. Biomater. 2016, 104, 686-697. [CrossRef] [PubMed]

15. Chen, Q.Z.; Thompson, I.D.; Boccaccini, A.R. 45s5 bioglass-derived glass-ceramic scaffolds for bone tissue engineering. Biomaterials 2006, 27, 2414-2425. [CrossRef] [PubMed]

16. Kim, I.; Lee, S.S.; Bae, S.; Lee, H.; Hwang, N.S. Heparin functionalized injectable cryogel with rapid shape-recovery property for neovascularization. Biomacromolecules 2018, 19, 2257-2269. [CrossRef] [PubMed]

17. Kumari, J.; Kumar, A. Development of polymer based cryogel matrix for transportation and storage of mammalian cells. Sci. Rep. 2017, 7, 41551. [CrossRef] [PubMed]

18. Savina, I.N.; Galaev, I.Y.; Mattiasson, B. Ion-exchange macroporous hydrophilic gel monolith with grafted polymer brushes. J. Mol. Recognit. 2006, 19, 313-321. [CrossRef] [PubMed] 
19. Baker, M.I.; Walsh, S.P.; Schwartz, Z.; Boyan, B.D. A review of polyvinyl alcohol and its uses in cartilage and orthopedic applications. J. Biomed. Mater. Res. B Appl. Biomater. 2012, 100, 1451-1457. [CrossRef] [PubMed]

20. Rahman, C.V.; Kuhn, G.; White, L.J.; Kirby, G.T.; Varghese, O.P.; McLaren, J.S.; Cox, H.C.; Rose, F.R.; Muller, R.; Hilborn, J.; et al. Plga / peg-hydrogel composite scaffolds with controllable mechanical properties. J. Biomed. Mater. Res. B Appl. Biomater. 2013, 101, 648-655. [CrossRef] [PubMed]

21. Hahn, M.S.; Taite, L.J.; Moon, J.J.; Rowland, M.C.; Ruffino, K.A.; West, J.L. Photolithographic patterning of polyethylene glycol hydrogels. Biomaterials 2006, 27, 2519-2524. [CrossRef] [PubMed]

22. Yamamoto, M.; Ikada, Y.; Tabata, Y. Controlled release of growth factors based on biodegradation of gelatin hydrogel. J. Biomater. Sci. Polym. Ed. 2001, 12,77-88. [CrossRef] [PubMed]

23. Wu, S.; Duan, B.; Lu, A.; Wang, Y.; Ye, Q.; Zhang, L. Biocompatible chitin/carbon nanotubes composite hydrogels as neuronal growth substrates. Carbohydr. Polym. 2017, 174, 830-840. [CrossRef] [PubMed]

24. Koshy, S.T.; Ferrante, T.C.; Lewin, S.A.; Mooney, D.J. Injectable, porous, and cell-responsive gelatin cryogels. Biomaterials 2014, 35, 2477-2487. [CrossRef] [PubMed]

25. Davidenko, N.; Schuster, C.F.; Bax, D.V.; Farndale, R.W.; Hamaia, S.; Best, S.M.; Cameron, R.E. Evaluation of cell binding to collagen and gelatin: A study of the effect of $2 \mathrm{~d}$ and $3 \mathrm{~d}$ architecture and surface chemistry. J. Mater. Sci. Mater. Med. 2016, 27, 148. [CrossRef] [PubMed]

26. Mazaki, T.; Shiozaki, Y.; Yamane, K.; Yoshida, A.; Nakamura, M.; Yoshida, Y.; Zhou, D.; Kitajima, T.; Tanaka, M.; Ito, Y.; et al. A novel, visible light-induced, rapidly cross-linkable gelatin scaffold for osteochondral tissue engineering. Sci. Rep. 2014, 4, 4457. [CrossRef] [PubMed]

27. Son, T.I.; Sakuragi, M.; Takahashi, S.; Obuse, S.; Kang, J.; Fujishiro, M.; Matsushita, H.; Gong, J.; Shimizu, S.; Tajima, Y.; et al. Visible light-induced crosslinkable gelatin. Acta Biomater. 2010, 6, 4005-4010. [CrossRef] [PubMed]

28. Han, M.E.; Kang, B.J.; Kim, S.H.; Kim, H.D.; Hwang, N.S. Gelatin-based extracellular matrix cryogels for cartilage tissue engineering. J. Ind. Eng. Chem. 2017, 45, 421-429. [CrossRef]

29. Chen, Y.C.; Lin, R.Z.; Qi, H.; Yang, Y.; Bae, H.; Melero-Martin, J.M.; Khademhosseini, A. Functional human vascular network generated in photocrosslinkable gelatin methacrylate hydrogels. Adv. Funct. Mater. 2012, 22, 2027-2039. [CrossRef] [PubMed]

30. Zuo, Y.; Liu, X.; Wei, D.; Sun, J.; Xiao, W.; Zhao, H.; Guo, L.; Wei, Q.; Fan, H.; Zhang, X. Photo-cross-linkable methacrylated gelatin and hydroxyapatite hybrid hydrogel for modularly engineering biomimetic osteon. ACS Appl. Mater. Interfaces 2015, 7, 10386-10394. [CrossRef] [PubMed]

31. Rahaman, M.N.; Day, D.E.; Bal, B.S.; Fu, Q.; Jung, S.B.; Bonewald, L.F.; Tomsia, A.P. Bioactive glass in tissue engineering. Acta Biomater. 2011, 7, 2355-2373. [CrossRef] [PubMed]

32. Gerhardt, L.C.; Boccaccini, A.R. Bioactive glass and glass-ceramic scaffolds for bone tissue engineering. Materials 2010, 3, 3867-3910. [CrossRef] [PubMed]

33. Ros-Tarraga, P.; Rabadan-Ros, R.; Murciano, A.; Meseguer-Olmo, L.; De Aza, P.N. Assessment of effects of si-ca-p biphasic ceramic on the osteogenic differentiation of a population of multipotent adult human stem cells. Materials 2016, 9, 969. [CrossRef] [PubMed]

34. Barradas, A.M.; Fernandes, H.A.; Groen, N.; Chai, Y.C.; Schrooten, J.; van de Peppel, J.; van Leeuwen, J.P.; van Blitterswijk, C.A.; de Boer, J. A calcium-induced signaling cascade leading to osteogenic differentiation of human bone marrow-derived mesenchymal stromal cells. Biomaterials 2012, 33, 3205-3215. [CrossRef] [PubMed]

35. Kendrick, J.; Chonchol, M. The role of phosphorus in the development and progression of vascular calcification. Am. J. Kidney Dis. 2011, 58, 826-834. [CrossRef] [PubMed]

36. Lin, F.H.; Yao, C.H.; Huang, C.W.; Liu, H.C.; Sun, J.S.; Wang, C.Y. The bonding behavior of dp-bioglass and bone tissue. Mater. Chem. Phys. 1996, 46, 36-42. [CrossRef]

37. Gomez-Vega, J.M.; Saiz, E.; Tomsia, A.P.; Marshall, G.W.; Marshall, S.J. Bioactive glass coatings with hydroxyapatite and bioglass particles on ti-based implants. 1. Processing. Biomaterials 2000, 21, 105-111. [CrossRef]

38. Qu, T.; Liu, X. Nano-structured gelatin/bioactive glass hybrid scaffolds for the enhancement of odontogenic differentiation of human dental pulp stem cells. J. Mater. Chem. B 2013, 1, 4764-4772. [CrossRef] [PubMed]

39. Allan, I.U.; Tolhurst, B.A.; Shevchenko, R.V.; Dainiak, M.B.; Illsley, M.; Ivanov, A.; Jungvid, H.; Galaev, I.Y.; James, S.L.; Mikhalovsky, S.V.; et al. An in vitro evaluation of fibrinogen and gelatin containing cryogels as dermal regeneration scaffolds. Biomater. Sci. 2016, 4, 1007-1014. [CrossRef] [PubMed] 
40. Murphy, C.M.; Haugh, M.G.; O’Brien, F.J. The effect of mean pore size on cell attachment, proliferation and migration in collagen-glycosaminoglycan scaffolds for bone tissue engineering. Biomaterials 2010, 31, 461-466. [CrossRef] [PubMed]

41. Hutson, C.B.; Nichol, J.W.; Aubin, H.; Bae, H.; Yamanlar, S.; Al-Haque, S.; Koshy, S.T.; Khademhosseini, A. Synthesis and characterization of tunable poly(ethylene glycol): Gelatin methacrylate composite hydrogels. Tissue Eng. Part A 2011, 17, 1713-1723. [CrossRef] [PubMed]

42. Hong, Z.; Reis, R.L.; Mano, J.F. Preparation and in vitro characterization of novel bioactive glass ceramic nanoparticles. J. Biomed. Mater. Res. A 2009, 88, 304-313. [CrossRef] [PubMed]

43. Constantz, B.R.; Ison, I.C.; Fulmer, M.T.; Poser, R.D.; Smith, S.T.; Vanwagoner, M.; Ross, J.; Goldstein, S.A.; Jupiter, J.B.; Rosenthal, D.I. Skeletal repair by in-situ formation of the mineral phase of bone. Science 1995, 267, 1796-1799. [CrossRef] [PubMed]

44. Ishikawa, K.; Ducheyne, P.; Radin, S. Determination of the ca/p ratio in calcium-deficient hydroxyapatite using x-ray-diffraction analysis. J. Mater. Sci. Mater. Med. 1993, 4, 165-168. [CrossRef]

45. Benton, J.A.; DeForest, C.A.; Vivekanandan, V.; Anseth, K.S. Photocrosslinking of gelatin macromers to synthesize porous hydrogels that promote valvular interstitial cell function. Tissue Eng. Part A 2009, 15, 3221-3230. [CrossRef] [PubMed]

46. Hanawa, T.; Kamiura, Y.; Yamamoto, S.; Kohgo, T.; Amemiya, A.; Ukai, H.; Murakami, K.; Asaoka, K. Early bone formation around calcium-ion-implanted titanium inserted into rat tibia. J. Biomed. Mater. Res. 1997, 36, 131-136. [CrossRef]

47. Maeda, H.; Kasuga, T.; Hench, L.L. Preparation of poly (L-lactic acid)-polysiloxane-calcium carbonate hybrid membranes for guided bone regeneration. Biomaterials 2006, 27, 1216-1222. [CrossRef] [PubMed]

48. Khan, A.F.; Saleem, M.; Afzal, A.; Ali, A.; Khan, A.; Khan, A.R. Bioactive behavior of silicon substituted calcium phosphate based bioceramics for bone regeneration. Mater. Sci. Eng. C Mater. Biol. Appl. 2014, 35, $245-252$. [CrossRef] [PubMed]

49. Shie, M.Y.; Ding, S.J.; Chang, H.C. The role of silicon in osteoblast-like cell proliferation and apoptosis. Acta Biomater. 2011, 7, 2604-2614. [CrossRef] [PubMed]

50. Boonrungsiman, S.; Gentleman, E.; Carzaniga, R.; Evans, N.D.; McComb, D.W.; Porter, A.E.; Stevens, M.M. The role of intracellular calcium phosphate in osteoblast-mediated bone apatite formation. Proc. Natl. Acad. Sci. USA 2012, 109, 14170-14175. [CrossRef] [PubMed]

51. Shekaran, A.; Garcia, A.J. Extracellular matrix-mimetic adhesive biomaterials for bone repair. J. Biomed. Mater. Res. A 2011, 96, 261-272. [CrossRef] [PubMed]

52. Mansour, A.; Mezour, M.A.; Badran, Z.; Tamimi, F. Extracellular matrices for bone regeneration: A literature review. Tissue Eng. Part A 2017, 23, 1436-1451. [CrossRef] [PubMed]

53. Hixon, K.R.; Eberlin, C.T.; Lu, T.; Neal, S.M.; Case, N.D.; McBride-Gagyi, S.H.; Sell, S.A. The calcification potential of cryogel scaffolds incorporated with various forms of hydroxyapatite for bone regeneration. Biomed. Mater. 2017, 12, 025005. [CrossRef] [PubMed]

54. Kim, H.D.; Jang, H.L.; Ahn, H.Y.; Lee, H.K.; Park, J.; Lee, E.S.; Lee, E.A.; Jeong, Y.H.; Kim, D.G.; Nam, K.T.; et al. Biomimetic whitlockite inorganic nanoparticles-mediated in situ remodeling and rapid bone regeneration. Biomaterials 2017, 112, 31-43. [CrossRef] [PubMed]

55. Pluharova, E.; Baer, M.D.; Mundy, C.J.; Schmidt, B.; Jungwirth, P. Aqueous cation-amide binding: Free energies and ir spectral signatures by ab initio molecular dynamics. J. Phys Chem. Lett. 2014, 5, 2235-2240. [CrossRef] [PubMed]

56. Wu, C.; Chang, J.; Zhai, W.; Ni, S. A novel bioactive porous bredigite (ca7mgsi4o16) scaffold with biomimetic apatite layer for bone tissue engineering. J. Mater. Sci. Mater. Med. 2007, 18, 857-864. [CrossRef] [PubMed]

57. Ghomi, H.; Fathi, M.H.; Edris, H. Effect of the composition of hydroxyapatite/bioactive glass nanocomposite foams on their bioactivity and mechanical properties. Mater. Res Bull. 2012, 47, 3523-3532. [CrossRef]

58. Hench, L.L. Bioceramics-From concept to clinic. J. Am. Ceram. Soc. 1991, 74, 1487-1510. [CrossRef]

59. Filgueiras, M.R.; La Torre, G.; Hench, L.L. Solution effects on the surface reactions of a bioactive glass. J. Biomed. Mater. Res. 1993, 27, 445-453. [CrossRef] [PubMed]

60. Jones, J.R.; Sepulveda, P.; Hench, L.L. Dose-dependent behavior of bioactive glass dissolution. J. Biomed. Mater. Res. 2001, 58, 720-726. [CrossRef] [PubMed] 
61. Kaur, G.; Pickrell, G.; Kimsawatde, G.; Homa, D.; Allbee, H.A.; Sriranganathan, N. Synthesis, cytotoxicity, and hydroxyapatite formation in 27-tris-sbf for sol-gel based cao-p2o5-sio2-b2o3-zno bioactive glasses. Sci. Rep. 2014, 4, 4392. [CrossRef] [PubMed]

62. Rezwan, K.; Chen, Q.Z.; Blaker, J.J.; Boccaccini, A.R. Biodegradable and bioactive porous polymer/inorganic composite scaffolds for bone tissue engineering. Biomaterials 2006, 27, 3413-3431. [CrossRef] [PubMed]

63. Nakamura, S.; Matsumoto, T.; Sasaki, J.; Egusa, H.; Lee, K.Y.; Nakano, T.; Sohmura, T.; Nakahira, A. Effect of calcium ion concentrations on osteogenic differentiation and hematopoietic stem cell niche-related protein expression in osteoblasts. Tissue Eng. Part A 2010, 16, 2467-2473. [CrossRef] [PubMed]

64. Maeno, S.; Niki, Y.; Matsumoto, H.; Morioka, H.; Yatabe, T.; Funayama, A.; Toyama, Y.; Taguchi, T.; Tanaka, J. The effect of calcium ion concentration on osteoblast viability, proliferation and differentiation in monolayer and 3d culture. Biomaterials 2005, 26, 4847-4855. [CrossRef] [PubMed]

(C) 2018 by the authors. Licensee MDPI, Basel, Switzerland. This article is an open access article distributed under the terms and conditions of the Creative Commons Attribution (CC BY) license (http://creativecommons.org/licenses/by/4.0/). 